\title{
Studies on Modeling and Physicochemical Properties of Oil Extracted from Moringa stenopetala Seed
}

\author{
Lema Deme Shumi (i) and Ebise Getacho Bacha (iD \\ School of Chemical Engineering, Jimma Institute of Technology, Jimma University, Jimma, Ethiopia \\ Correspondence should be addressed to Lema Deme Shumi; lemmiye@gmail.com
}

Received 3 November 2021; Revised 12 January 2022; Accepted 13 January 2022; Published 8 February 2022

Academic Editor: Gianfranco Carotenuto

Copyright (C) 2022 Lema Deme Shumi and Ebise Getacho Bacha. This is an open access article distributed under the Creative Commons Attribution License, which permits unrestricted use, distribution, and reproduction in any medium, provided the original work is properly cited.

\begin{abstract}
Moringa stenopetala, locally known as Shiferraw, is an indigenous vegetable tree native to southern Ethiopia and grown mainly for its food value. This study deals with the investigations of physicochemical characteristics of Moringa stenopetala seeds' oil extracted using solvent extraction with food-grade hexane as a solvent and Analysis of Variance (ANOVA) of the extraction parameters. The seeds were collected from Adama located in Oromia, East Shewa Zone of Ethiopia, and they exhibit the average moisture, ash, fiber, protein, and oil contents of $6.3,4.2,2.3,27.5$, and $40.2 \%$, respectively. Temperature, extraction time, and particle size had a significant $(p<0.05)$ effect on the oil yield. According to the Experimental Design Response Surface Methodology (RSM) and ANOVA analysis, the optimum process parameters' combination to find the highest oil yield was particle size of $0.83 \mathrm{~mm}$, the temperature at $78.82^{\circ} \mathrm{C}$, and extraction time of 5.13 hours. The model predicted oil yield was $39.7 \pm 0.32 \%$. The oil from Moringa stenopetala seed exhibits physiochemical characteristics of refractive index $\left(40^{\circ} \mathrm{C}\right), 1.4625$; viscosity $49.4 \mathrm{Cp}$; density at $25^{\circ} \mathrm{C}, 0.9317 \mathrm{~g} / \mathrm{cm}^{-3}$; saponification value, 191.4 ; peroxide value, $11.52 \mathrm{millieq} \mathrm{O}_{2} / \mathrm{kg}$; iodine value of 89.21; and Acid Value (AV) $2.21 \mathrm{mg} \mathrm{KOH} / \mathrm{g}$. Fourier-transform infrared spectroscopy (FT-IR) analysis shows that the oil contains both ester carbonyl $(C=O)$ functional groups saturated and unsaturated fatty acid. The physicochemical properties of Moringa stenopetala seeds were compared with other edible oil properties such as sesame, groundnut, olive, and sunflower seeds. The result shows that in the future Moringa stenopetala could be used as a substitute for other oil-bearing seeds sources, such as soybean, sunflower, and groundnut.
\end{abstract}

\section{Introduction}

Vegetable oils are derived from the seeds and fruits of plants that are grown in different parts of the world. Several hundred varieties of plants were known to have oil-bearing seeds. However, a few only become commercially significant such as soybean, cotton, groundnut, sunflower, linseed, olive, sesame, castor, coconut, and oil palm seeds [1]. In Ethiopia, there are underutilized plants that have the potential to bring a lot of prosperity. One of the underutilized plants is Moringa stenopetala. This plant could be cultivated easily with cheap expenditure and can well grow comfortably in Ethiopia. Moringa stenopetala, colloquially called Shiferraw in local, is inherent to the southern parts of Ethiopia. It is drought-tolerant and growing fast and also has high nutritional value. It can be the potential to alleviate malnutrition in the tropics [2].

Like other vegetables, the leaves and the young green pods can be taken as food supplements. The seed can be crushed to obtain high-grade oil. Moringa seeds' oil (MSO) is well known to be highly valued in the cosmetic industry for its unique property of being light and easily spread on the skin. It is observed to be the best for massage and aromatherapy applications [3]. Thus, the development of an oil extraction process with the optimum condition is of immense importance because both oilseeds and the edible oil processing industry in Ethiopia are still underdeveloped to a large extent and the imported oil put the local edible oil industry under additional requirements $[3,4]$. Furthermore, attention and research are necessary for enhancing the 


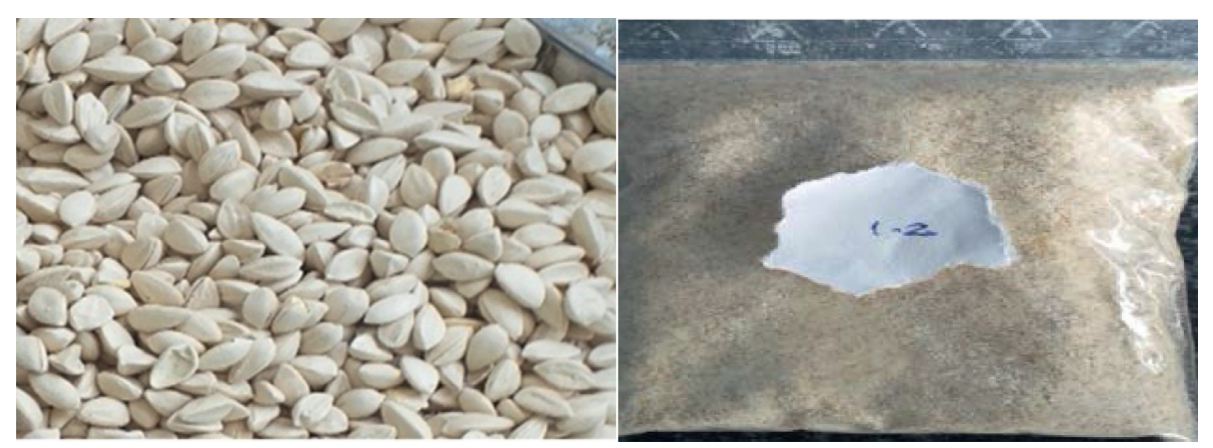

Figure 1: A seed sample of Moringa stenopetala seeds.

quality, specifically for the culinary purpose of Moringa stenopetala oil.

This work squeezes the extraction and characterization of Moringa stenopetala seed oil by using solvent extraction technology. The necessary proximate composition of Moringa seed is determined and compared with the other edible oil seeds composition. The solvent extraction method is the most popular method of oil extraction because of its high percentage of oil recovery from seeds. The process parameters like particle size, extraction time, and temperature are optimized and analyzed by using the ANOVA method. The physicochemical properties of oil produced at optimum parameters are studied and compared with other edible seeds' oil.

\section{Materials and Methods}

2.1. Chemicals and Materials. Chemicals and raw materials used in the extraction and characterization of oil were Moringa stenopetala seeds, $n$-hexane, ethanol, sodium thiosulphate, starch, sulfuric acid, potassium iodide (KI), hydrochloric acid ( $\mathrm{HCl}), \mathrm{H} 2 \mathrm{SO} 4$, and $0.1 \mathrm{~N} \mathrm{Na2S2O3.} \mathrm{All}$ chemicals were analytical-grade ingredients and procured from heparin and volumetric chemicals, Addis Ababa, Ethiopia. The equipment used were crusher, sieves, oven, muffle furnace, fiber analyzer, fat analyzer, Soxhlet setup, electric heater, digital weight balance, viscometer, refractometer, rotary evaporator, pipettes, biuret, titration setup, and FT-IR.

2.2. Sample Preparation. Samples of Moringa seeds were cleaned by removing unwanted impurities. Further, the samples were grounded to reach standard homogenous powder to increase the surface-to-volume ratio that enhances the solvent extraction. The prepared samples were sieved to collect three different particle sizes of $0.3,0.75$, and $1.2 \mathrm{~mm}$ as shown in Figure 1. The samples were kept away from light at room temperature using air-tight polyethylene bags for further experiments.

2.3. Proximate Analysis of Moringa stenopetala Seeds. Proximate analysis of Moringa stenopetala seeds sample for determining moisture, ash, crude protein, crude fiber, and oil yield was carried out by adopting [5] methods.
2.4. Experimental Design for MSO Extraction. RSM is a proven technique that consists of statistical and mathematical approaches for building models. Also, the effect of selected factors can be evaluated. It is used to determine the optimal condition within a predetermined range [6, 7]. In this study, the influence of the chosen operating parameters temperature $(T)$, extraction time $(t)$, and particle size $(S)$ and the output variable (MSO yield) were evaluated using RSM. The output variable, oil yield (\%), can be represented as a function of the selected variables, as given in the following equation.

$$
\text { yield }=p_{O}+\sum_{i=1}^{n} b_{i} X_{i}+\sum_{i=1}^{n} b_{i i} X_{i}^{2}+\sum_{i=1}^{n-1} \sum_{j=2}^{n} b_{i j} X_{i} X_{j}+\lambda
$$

$X 1, X 2, \ldots, X n$ refer to the input independent factors that can affect the output yield; $n$ refers to the number of parameters, $p_{0}$ is nothing but the constant, $b_{i i}$ $(i=1,2, \ldots, n)$ denotes the quadratic term coefficient, $b_{i j}$ $(i=1,2, \ldots, n ; j=1,2, \ldots, n)$ refers to the interaction term coefficient, and $\lambda$ is the random error. In this study, the response was extraction yield of MSO and the chosen independent factors were temperature, time, and particle size of the seed.

Soxhlet apparatus was used for extracting the oil from the Moringa seeds. Crushed Moringa seeds ( $20 \mathrm{~g}$ ) were taken into a Soxhlet extraction apparatus. The food-grade solvent (hexane, $200 \mathrm{~mL}$ ) was taken into a round bottom distillation container. The Soxhlet extraction apparatus was heated up to obtain extracted oil for the predetermined time. The extracted oil was condensed and collected.

Extraction was carried out for predetermined combinations of the chosen process parameters, temperature, particle size, and extraction time. Table 1 shows the maximum, minimum, and average values of selected independent parameters that had been taken for this experiment. The experiments were planned with the aid of Design Expert Software by applying a Box-Behnken design (BBD). BBD provides a predetermined experimental design for the combination of the parameters. Based on BBD, eighteen (18) runs of extraction experiments were conducted.

Based on these combinations, in each cycle, $10 \mathrm{~g}$ of seed powder sample was taken to extract oil using $120 \mathrm{~mL}$ of food-grade hexane as a solvent with a solid-to-liquid ratio of $1: 12(w / v)$. At the end of each cycle, the thimble was 
TABLE 1: Levels of chosen parameters for experimental design.

\begin{tabular}{lcccc}
\hline Factors & Units & $\begin{array}{c}\text { Minimum } \\
(-1)\end{array}$ & $\begin{array}{c}\text { Average } \\
(0)\end{array}$ & $\begin{array}{c}\text { Maximum } \\
(+1)\end{array}$ \\
\hline Temperature & ${ }^{\circ} \mathrm{C}$ & 68 & 76.5 & 85 \\
Time & $\mathrm{h}$ & 3.5 & 4.75 & 6 \\
Particle size & $\mathrm{mm}$ & 0.3 & 0.75 & 1.2 \\
\hline
\end{tabular}

withdrawn from the setup and dried in the oven for $1 \mathrm{~h}$ at $105^{\circ} \mathrm{C}$. The amount of the extracted oil was determined by separating the final dried thimble with powder mass from the initial thimble with seed powder mass. Based on the oil mass the concentration of oil in the solvent (hexane) was calculated for each cycle of extraction. Further, the extracted oil was stored in a bottle in the refrigerator for further analysis.

2.5. Determination of Oil Yield. The yield of oil is favorably determined by the processing parameters and its values. The oil yield from the extraction was calculated using thefollowing equation.

$$
\text { Yield of oil }(\%)=\frac{L_{1}-L_{2}}{L_{1}} \times 100,
$$

where $L_{1}$ refers to the weight of the seed sample before extraction and $L_{2}$ refers to the weight of the sample after extraction that dried in the oven.

2.6. Determination of Physical Properties of MSO. The specific gravity of oil was estimated using a pycnometer bottle by adopting [8]. The relationship is given as follows.

$$
\text { Specific gravity }(S G)=\frac{W_{O}-W}{W_{1}-W},
$$

where $W=$ weight of empty bottles, $W o=$ weight of the empty bottle and the oil, and $W 1=$ weight of the bottle and distilled water content.

Dynamic viscosity of MSO was assessed using vibroviscometer (TA Instruments, ARES-G2). Then, the kinematic viscometer was calculated using the following relationship.

$$
\text { Kinematic viscosity }=\frac{\text { dynamic viscosity of MSO }}{\text { desnsity of MSO }} \text {. }
$$

The Refractive Index (RI) of the MSO was examined using a refractometer (PCE Instruments-DRB 10).

2.7. Determination of Chemical Properties of MSO. To determine the acid value of the extracted MSO, the oil sample $(5 \mathrm{~g})$ was dissolved in a mixture of diethyl ether $(25 \mathrm{ml})$ and ethanol $(25 \mathrm{ml})$. Further, 3 drops of phenolphthalein were added. The available free acid present in the oil sample was titrated against standard $0.1 \mathrm{~N} \mathrm{KOH}$ solution. The appearance of the red color was considered to be an endpoint that should not fade within 10 seconds. The acid value can be determined using the following equation.

$$
\text { FFA of } \mathrm{MSO}=\frac{V \times N \times 56.1}{S_{O}},
$$

where $N$ is the concentration of $\mathrm{KOH}, 56.1$ is the equivalent weight of $\mathrm{KOH}, V$ is the consumed volume of $\mathrm{KOH}$, and $S_{o}$ is the weight of sample oil taken. Peroxide value, saponification value, and iodine value of the extracted MSO were also estimated by adopting standard [5] methodology. Analysis for the functional group present in the oil was carried out using the FT-IR spectrometer (iS50 ABX: Thermo Scientific, Germany). Fourier transform infrared spectrometer was preheated and stabilized with the solvent. The signals were received in 32 scans and $250 \mathrm{~cm}^{-1}$ resolutions. A sample of oil was taken using a pipette between two well-polished $\mathrm{KBr}$ disks that creates a thin film. The resulting spectra were observed from 4000 to $500 \mathrm{~cm}^{-1}$. They were analyzed using the software program Spectrum for Windows (PerkinElmer). After $10 \mathrm{~min}$, the software display transmittance (\%) versus absorption number $\left(\mathrm{cm}^{-1}\right)$ plot and their value corresponding to the functional group was analyzed.

\section{Results and Discussion}

3.1. Proximate Analysis on Moringa stenopetala Seeds. The average value of protein content of Moringa stenopetala seeds was determined to be $27.5 \%$ (by the Kjeldahl method). The results revealed that there was a significant difference in protein content with different peanut cultivars grown in Pakistan which ranged between 24.5 and $28.55 \%$ [9]. Sunflower kernels have been observed to be the $18.5 \%$ of protein content [10]. The protein content of Moringa stenopetala was observed to be higher than the values reported for protein content from other oil sources, which showed that the Moringa stenopetala seeds can be a higher protein source. The average value of fiber content in the Moringa stenopetala seed was found to be $2.3 \%$. For groundnut, fiber content value was reported in the range of $1.3-1.5 \%$ [10]. It showed that the Moringa has a higher content of fiber that helps to control blood sugar levels. The moisture content of Moringa stenopetala oilseed was found to be $6.3 \%$. The moisture content of the groundnut was reported elsewhere in the range of $4.7 \%$ to $5.1 \%$. The moisture content of the whole kernel of peanut varied between 3.9 and $13.2 \%$. The moisture content of the seed of three cultivars of groundnut varied between 4.8 and $5.1 \%$ as reported by [11]. However, the moisture content in the Moringa stenopetala seed is inconsistent with the literature. The presence of ash content in the Moringa stenopetala seeds was observed to be $4.2 \%$. As reported by [1], this value is slightly higher than that of sunflower seeds (3\%). Also, it was found that Moringa seed has higher ash content than groundnut as reported by [12], who found the range of $2.2 \%$ to $2.5 \%$ for three groundnut seeds.

3.2. MSO Extraction according to BBD Design of Experiment. To optimize the extraction process, the considered parameters, temperature $(T)$, time $(t)$, and particle size $(S)$, were grouped into different combinations as mentioned in 
Table 2. All the combinations were examined using the Soxhlet setup to extract MSO. Extraction was carried out in duplicated experiments and the mean values of oil yield from the experiments and predicted values of the corresponding combinations are given below.

\subsection{Construction of RSM Model for Extraction of MSO.} Selection of equation of the model is a crucial need that provides good enough knowledge for process modeling. Further, the analysis of the statistical significance of model terms is also much important for the potential optimization of oil yield maximization. Based on the experimental design of the MSO yield (fed as a response) and the evaluated ANOVA analysis, equation models were acquired. Table 3 presents the observed values of standard deviation, $R^{2}, R^{2}$ (predicted), $R^{2}$ (adjusted), and its significance for different types of models.
From the observed results, the quadratic model had greater significance. Also, the quadratic model showed a nonsignificance to lack of fitness. So, the quadratic model can be deliberated for describing the oil yield correlation with the independent parameters. The coefficient of determination $\left(R^{2}\right)$ and adjusted coefficient of determination $\left(R^{2}\right.$ adj) are 0.95683 and 0.908264 , respectively, which indicated that the estimated model fits the experimental data properly. The value of $R^{2}$ for the developed correlation is 0.95683 . It implies that $95.68 \%$ of the total variation in the percentage of yield is attributed to the experimental variables studied. Reference [6] suggested that for a good fit of a model, $R^{2}$ should be at least $0.85 . R^{2}$ for these response variables was higher than 0.85 , indicating that the regression models explained the actual response. The process model for extraction of MSO in terms of the quadratic model is given in the following equation.

$$
\begin{aligned}
\text { Yield of } M S O= & +39.17+1.86 \times T+1.14 \times t+1.15 \times S-1.25 \times t \times T \\
& +0.52 \times T \times S+0.47 \times t \times S-2.88 \times T^{2}-1.47 t^{2}-3.96 S^{2} .
\end{aligned}
$$

Figure 2 presents the normal plot of residuals and experimental versus the predicted oil yield. From the predicted versus actual plot, a linear distribution is observed, which is an indicator that the model is well fitting. The values predicted were close to the observed values of oil yield.

3.4. Analysis of the Variance of the Model. Analysis of variance (ANOVA) for the process model is given in Table 4. The table shows the significance of different terms.

ANOVA results showed that all the model terms, except TS and $t S$, were quite significant. The model terms, TS and $\mathrm{tS}$, had $P$-values greater than 0.05 . That pointed to the fact that the model terms were not significantly correlated. The F-value of the "Lack of Fit" was found to be 0.1690 , which showed the nonsignificance result. That proposes the lack of fit occurred relative to the pure error. So, it is clear that the obtained equation holds very good for model fit.

\subsection{Effect of Individuals Factors}

3.5.1. Effect of Temperature on Extraction of MSO. The effect of temperature on MSO yield is described graphically in Figure 3(a). The extraction was carried out at three different temperatures $\left(68,77.5\right.$, and $\left.85^{\circ} \mathrm{C}\right)$. Extraction at above the boiling point gives higher oil yield as a result of decreasing in viscosity of the solvent favorable to its flowing through and the solubility of the oil in the solid increases, but as the temperature increases further, the evaporation rate of the solvent increases, which may reduce the contact time between the solvent and solid and maymbe the cause for lower oil yield at a temperature above $78{ }^{\circ} \mathrm{C}$.
3.5.2. Effect of Extraction Time. The effect of extraction time on MSO yield is described graphically in Figure 3(b). The extraction was carried out at three different extraction times $(3.5,4.75$, and 6 hours). The oil yield did not have a significant change after $4: 45 \mathrm{~h}$ because most of the oil is extracted in the first four hours and only a small increase of yield is obtained from $4: 45-6$ hours of extraction although maximum extracted oil is achieved after $4.75 \mathrm{~h}$.

3.5.3. Effect of Particle Size on MSO. The effect of particle size on extraction yield at extraction time of $4.75 \mathrm{~h}$ and temperature of $77^{\circ} \mathrm{C}$ was shown in Figure 3(c). The highest percentage of oil yield was obtained from a $0.75 \mathrm{~mm}$ size sample, which is $40.1 \%$. Lower oil yield was found from the larger particles larger than $0.3 \mathrm{~mm}$ compared to the smaller size particles. The reason is that larger particles have smaller contact surface areas and are more resistant to the solvent entrance and oil diffusion distance to the external surface. Therefore, less amount oil will be transferred from inside the larger particles to the surrounding solution in comparison with the smaller ones. However, when the particle is too small (i.e., below $0.5 \mathrm{~mm}$ ), less oil can be extracted even though the contact surface area for the small particle is supposed to be significantly higher than the larger particles. This may be due to the agglomeration structure of the fine particles, which reduces the effective surface area available for the free flow of solvent to solid. This prevents free interactions between solid and solvent.

3.6. Interaction Effect of the Parameters. Based on preliminary BBD, Response Surface Methodology (RSM) was employed to find the interaction effect and optimization of 
TABLE 2: Box-Behnken design of parameters and the response actual and predicted values.

\begin{tabular}{|c|c|c|c|c|c|}
\hline Run & $A=$ temperature $\left({ }^{\circ} \mathrm{C}\right)$ & Time $(\mathrm{h})$ & Particle size $(\mathrm{mm})$ & Actual yield (\%) & Predicted value (\%) \\
\hline 1 & 76.5 & 4.75 & 0.75 & 38.2 & 39.17 \\
\hline 2 & 85 & 6 & 0.75 & 37.4 & 36.60 \\
\hline 3 & 85 & 4.75 & 0.3 & 32.1 & 32.51 \\
\hline 4 & 76.5 & 4.75 & 0.75 & 39.8 & 39.17 \\
\hline 5 & 68 & 4.75 & 0.3 & 30.9 & 29.84 \\
\hline 6 & 68 & 4.75 & 1.2 & 31.5 & 31.09 \\
\hline 7 & 85 & 3.5 & 0.75 & 37.5 & 36.83 \\
\hline 8 & 76.5 & 3.5 & 1.2 & 33.7 & 33.31 \\
\hline 9 & 76.5 & 3.5 & 0.3 & 31.7 & 31.96 \\
\hline 10 & 76.5 & 4.75 & 0.75 & 40.1 & 39.17 \\
\hline 11 & 68 & 6 & 0.75 & 34.7 & 35.38 \\
\hline 12 & 76.5 & 6 & 1.2 & 36.8 & 36.54 \\
\hline 13 & 68 & 3.5 & 0.75 & 29.8 & 30.60 \\
\hline 14 & 76.5 & 4.75 & 0.75 & 38.4 & 39.17 \\
\hline 15 & 76.5 & 4.75 & 0.75 & 38.7 & 39.17 \\
\hline 16 & 85 & 4.75 & 1.2 & 34.8 & 35.86 \\
\hline 17 & 76.5 & 6 & 0.3 & 32.9 & 33.29 \\
\hline 18 & 76.5 & 4.75 & 0.75 & 39.8 & 39.17 \\
\hline
\end{tabular}

TABLE 3: Statistical summary of the models.

\begin{tabular}{|c|c|c|c|c|c|}
\hline Model type & Std. Dev & $R^{2}$ & $\operatorname{Adj} R^{2}$ & Pred $R^{2}$ & Significance for lack of fitness \\
\hline Linear & 3.289326 & 0.243221 & 0.081054 & -0.16682 & Significant \\
\hline $2 \mathrm{FI}$ & 3.608327 & 0.284463 & -0.10583 & -0.95711 & Significant \\
\hline Quadratic & & 0.95683 & 0.908264 & 0.557573 & Nonsignificant \\
\hline Cubic & 0.826236 & 0.982947 & 0.942019 & - & Aliased \\
\hline
\end{tabular}

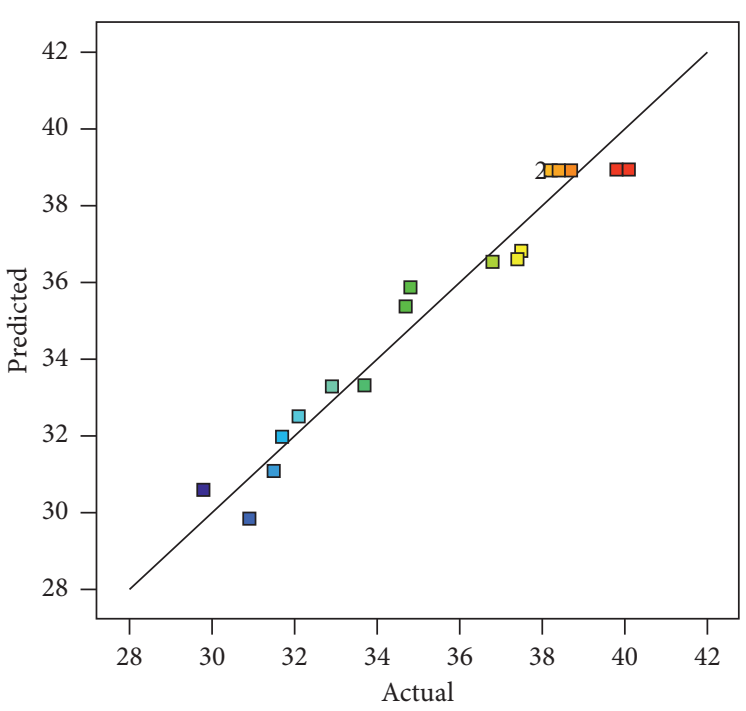

(a)

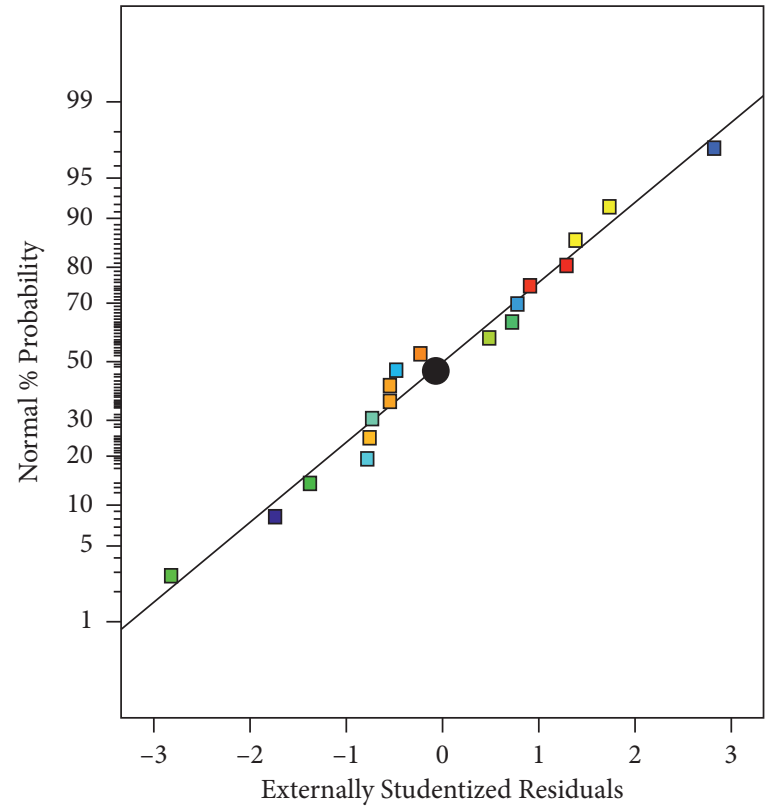

(b)

Figure 2: Analytical plots for adequacy of the proposed model. (a) Actual versus predicted plot. (b) Normal plot of residual.

MSO extraction. Temperature $(T)$, time $(t)$, and particle size $(S)$ were considered to be three different independent factors aiming to optimize for maximizing the oil yield.
Figure 4 shows that at the lower and higher temperature the oil yield was low and had a small increase as time increased. At the center point of temperature, the oil yield is 
TABLE 4: The analysis of variance (ANOVA) for the quadratic model.

\begin{tabular}{lccccc}
\hline Source & Sum of squares & Df & Mean square & $F$ value & $P$-value prob $>F$ \\
\hline Model & 191.5169 & 9 & 21.27966 & 19.70149 & 0.0002 \\
$T$ & 27.75125 & 1 & 27.75125 & 25.69312 & 0.0010 \\
$t$ & 10.35125 & 1 & 10.35125 & 9.583566 & 0.0148 \\
$S$ & 10.58 & 1 & 10.58 & 9.795352 & 0.0140 \\
$\mathrm{Tt}$ & 6.25 & 1 & 6.25 & 5.786479 & 0.0428 \\
$\mathrm{TS}$ & 1.1025 & 1 & 1.1025 & 1.020735 & 0.3419 \\
$\mathrm{tS}$ & 0.9025 & 1 & 0.9025 & 0.835568 & 0.3874 \\
$\mathrm{~T} 2$ & 36.27758 & 1 & 36.27758 & 33.58711 & 0.0004 \\
T2 & 8.964848 & 1 & 8.964848 & 8.299985 & 0.0205 \\
S2 & 68.37121 & 1 & 68.37121 & 63.30057 & $<0.0001$ \\
Residual & 8.640833 & 8 & 1.080104 & & 0.1690 \\
Lack of fit & 5.2275 & 3 & 1.7425 & 2.55249 & \\
Pure error & 3.413333 & 5 & 0.682667 & & NNot significant \\
Cor total & 200.1578 & 17 & & & \\
\hline
\end{tabular}

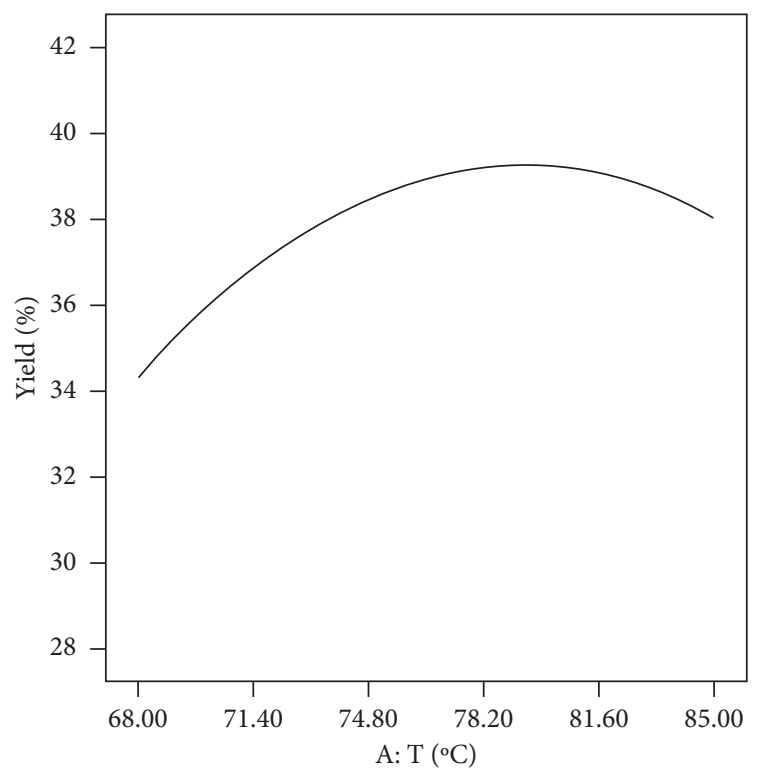

(a)

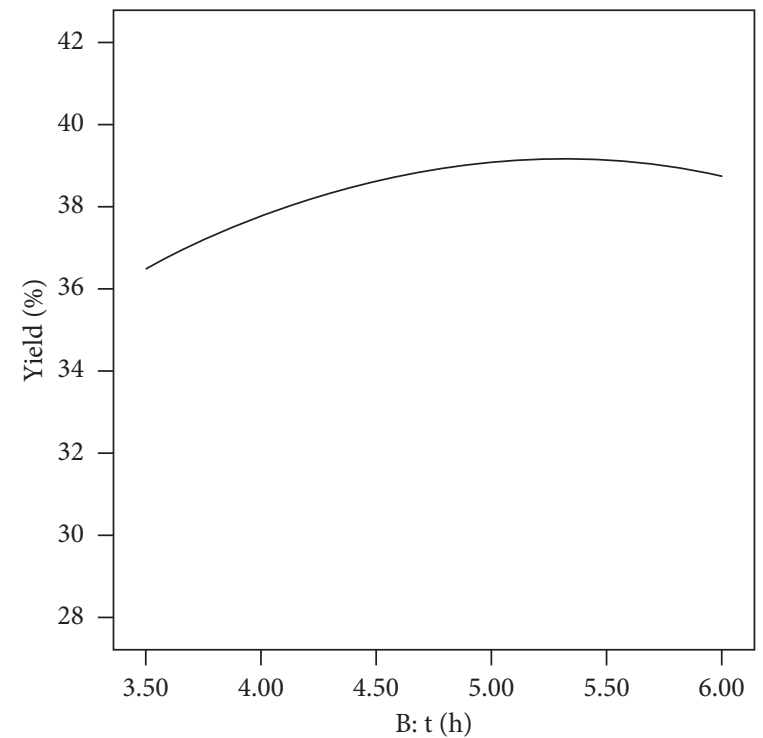

(b)

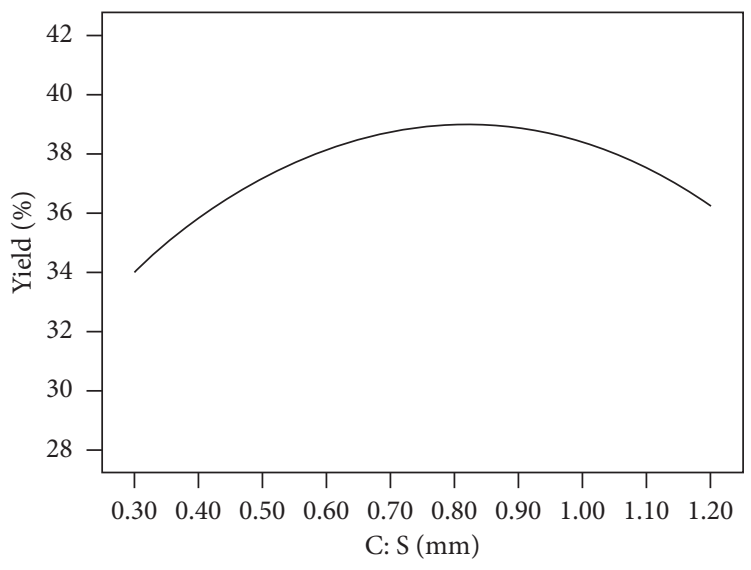

(c)

FIGURE 3: Individual effect of parameters. (a) Extraction temperature. (b) Extraction time. (c) Particle size effect on MSO. 


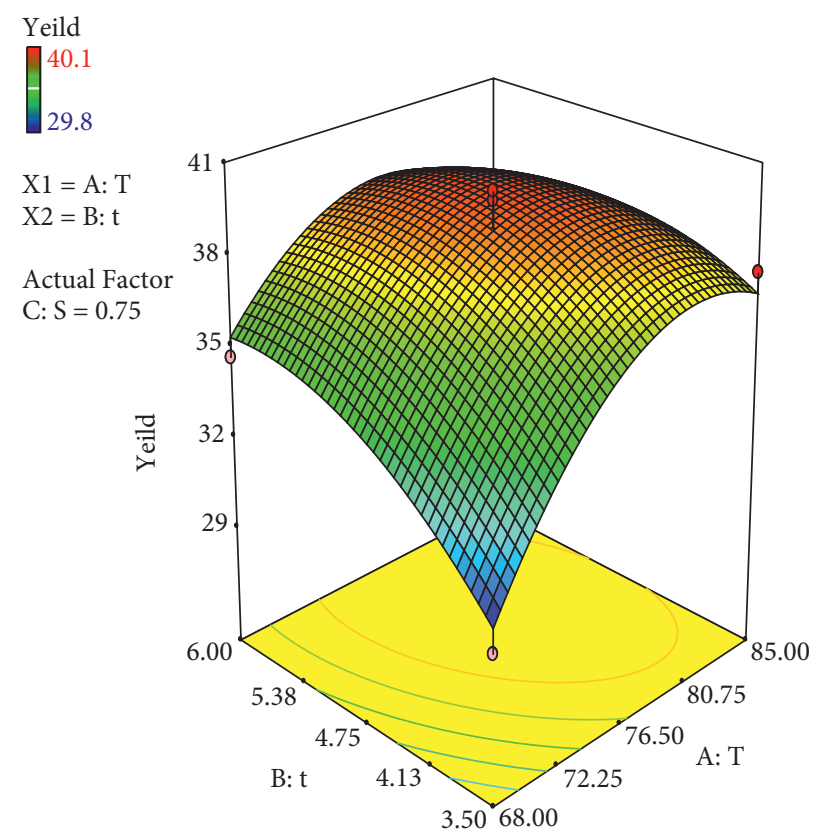

(a)

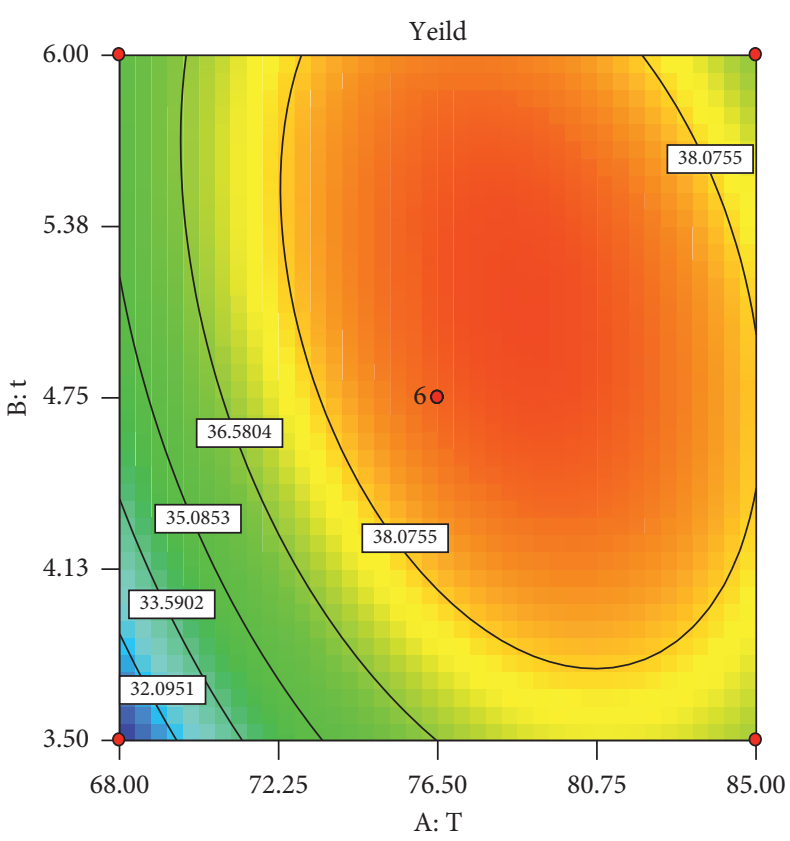

(b)

Figure 4: Interaction influence of extraction time and temperature on MSO yield, 3D surfaces plot. (b) Contour plots.

maximum. From this study, the interaction of extraction time and temperature higher oil yield (38.0755\%) is obtained at the middle of extraction time $(4.75 \mathrm{~h})$ and temperature of $77{ }^{\circ} \mathrm{C}$. At higher than the center point of temperature, oil yield is low. The reason is probably that as the temperature of the solvent increased above the boiling point, the viscosity of the solvent (hexane) decreased, and the solubility of oil in the solid increased. When the temperature further increased the evaporation rate increased and the contact time between the solvent and the solid decreased and that may be the cause for the reduction of oil yield at temperature increased above $80{ }^{\circ} \mathrm{C}$.

From the diagrams, the oil yield of the extraction significantly differs with temperature and extraction time. The findings concerning these parameters' relationship cleared that the increase in temperature increased the yield of oil. The interaction was found to be quite steep, and the mutual relation between temperature extraction time on oil yield was much significant. The interaction study explains that fixing an optimal combination of parameters conditions will significantly improve oil extraction. Owing to optimizing the selected parameter for maximizing the oil yield, the numerical solution was attempted through the software. From the RSM model, the optimized parameters were presented in Table 5 as follows.

3.7. Characterization of Acquired MSO. MSO sample obtained from solvent extraction using an optimized condition was subjected to different physical and chemical characterizations.

3.7.1. Refractive Index. The refractive index is the ratio of the velocity of light in a vacuum to the velocity in the medium being measured. The results showed that the refractive index
TABLE 5: The numerical solution to achieve maximized MSO yield.

\begin{tabular}{lc}
\hline Variables & Optimal condition \\
\hline Temperature $\left({ }^{\circ} \mathrm{C}\right)$ & 78.82 \\
Extraction time $(\mathrm{h})$ & 5.13 \\
Particle size $(\mathrm{mm})$ & 0.83 \\
Predicted oil yield $(\%)$ & $39.7 \pm 0.32 \%$ \\
Desirability level & 0.961 \\
\hline
\end{tabular}

of MSO is 1.4625 at $40 \mathrm{C}$. Refractive index for crude and refined groundnut oil varied from 1.463 to 1.466 [11]. The refractive index of peanut oil was mentioned as 1.367 and 1.465 at $40 \mathrm{C}$ [13]. The refractive indices for oils for some seed oils are1.465-1.469; 1.458-1.466; and 1.461-1.464 for, sesame, cotton, and sunflower oils, respectively [14]. The results, obtained in this study, showed that the refractive index value of moringa oil is within the range.

3.7.2. Kinematic Viscosity. The viscosity of MSO was determined by viscometer and the value was found 49.4 centistokes at room temperature. It is also lower than the values reported by other investigators. The viscosity of groundnut ranges from 40.0 to 52.43 centistokes [12]. It is reported that the initial viscosity of fresh oil extracted from newly harvested sunflower seeds is 54.1Cp $[15,16]$. The kinematic viscosity MSO is much near to the viscosity of other edible seeds' oil reported by different scholars.

3.7.3. Specific Gravity. The specific gravity of Moringa stenopetala seed oil was 0.9314 at room temperature. This value is higher compared to the range of $0.911-0.918$ reported by [17]. Reference [10] reported 0.915-0.924; 
$0.925-0.912 ; 0.918-0.926$; and $0.918-0.923$ specific gravity of sesame, groundnut, cotton, and sunflower oils, respectively. It is clear from the result obtained in this study that the specific gravity of moringa stenopetala seed oil is within the range reported for some seeds' oil.

3.7.4. Iodine Value/Number. The iodine value is a measurement of the degree of unsaturation of vegetable oils and an indicator of their exposure to oxidation. The iodine value of MSO was found to be 89.2 as iodine/100 $\mathrm{g}$ oil. The measurement of iodine value (IV) is one of the most convenient and simple methods to determine fat and oil deterioration [18]. The initial iodine values for cotton, sesame, and groundnut oils were reported to be 106.7, 103.5, and $97.5 \mathrm{mg} /$ iodine/100 g/fat, respectively [16]. The iodine value of soybean oil ranged from 82 to 107 [19]. This implies that the iodine value of MSO is good as compared to the other edible oils.

3.7.5. Peroxide Value. The peroxide value is an indicator of the extent of primary oxidation products and oxidative stability in the oil product [20]. The peroxide value of moringa oil was found to be 11.52 . The peroxide value of moringa oil was higher than the earlier findings of [21], who reported 7.98 for sunflower. It is also lower than the values recommended by [14] for oils of sesame (15.0), groundnut (15.0), cotton (13.0), and sunflower (15.0). The concentration of peroxide value is advantageous for assessing the extent to which spoilage has advanced. It gives the initial evidence of rancidity in unsaturated fats and oil [20].

3.7.6. Saponification Value. The saponification value is the amount of alkali needed to saponify a given quantity of fat or oil, expressed as mg potassium hydroxide to saponify $1 \mathrm{~g}$ sample. The value obtained was 191.4. A higher saponification value shows the shorter chain of fatty acids [22]. The value of saponification as $\mathrm{mg} \mathrm{KOH} / \mathrm{g}$ oil was $188-199$, 186-195, 186,196, and 189-199 for sunflower, sesame, groundnut, and cotton, respectively [10]. This shows that the saponification value of MSO is within the range recommended. The long-chain fatty acids found in fats have low saponification value because they have relatively fewer carboxylic functional value groups per unit mass of fat; therefore, they have a high molecular weight.

3.7.7. Free Fatty Acid Value. The percentage of Moringa stenopetala oil-free fatty acids (FFA) as oleic acids was calculated. It was found to be 2.21. The FFA value for fresh oil extracted from stored sunflower seeds was 2.112 [1]. The acid value for groundnut oil should not be more than $4 \mathrm{mg} / \mathrm{KOH} / \mathrm{g}$ oil as recommended in [22]. Acid values of 3.0-2.5 (sesame); 3.0-2.0 (groundnut); and 3.0-2.6 (cotton and sunflower) oils were reported by [10]. This shows that the value of free fatty acid of Moringa stenopetala oil is in the range of the recommended for groundnut, sunflower, and cotton oil.

Table 6 is a summary of the physicochemical properties of Moringa stenopetala seed oil.
TABLE 6: Summary of physicochemical properties of obtained MSO.

\begin{tabular}{lc}
\hline Physical parameter & Value \\
\hline Color & Brown \\
Specific gravity $\left(\mathrm{g} / \mathrm{cm}^{3}\right)$ & 0.9317 \\
Kinematic viscosity $(\mathrm{cp})$ & 49.4 \\
Density $\left(\mathrm{kg} / \mathrm{m}^{3}\right)$ & 930.7 \\
Refractive index $\left(\right.$ at $\left.40^{\circ} \mathrm{C}\right)$ & 1.4625 \\
Free fatty acids $(\mathrm{mg} \mathrm{KOH} / \mathrm{g})$ & 2.21 \\
Saponification value of oil $(\mathrm{mg} \mathrm{KOH} / \mathrm{g})$ & 191.4 \\
Peroxide value (meq. O $/ \mathrm{Kg}$ oil) & 11.52 \\
Iodine value $(\mathrm{I}$ g/100 g oil) & 89.21 \\
Oil yield (overall at optimal) & $39.5 \%$ \\
\hline
\end{tabular}

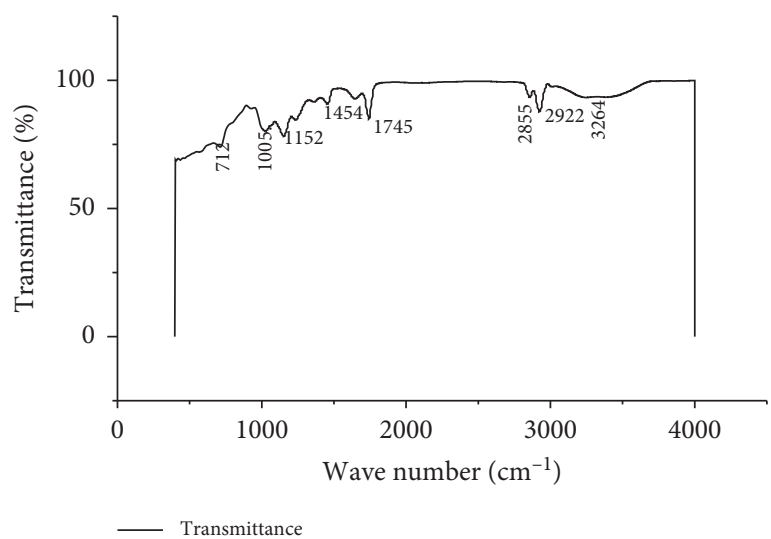

FIGURE 5: FT-IR spectrum of Moringa stenopetala seed oil.

3.7.8. FTIR Analysis (Determination of Functional Group). Additionally, the MSO sample was subjected to FT-IR analysis to examine the functional group. Figure 5 shows the plot of transmittance (\%) versus wavenumber $\left(\mathrm{cm}^{-1}\right)$ obtained from the FT-IR study. The peaks represent a specific functional group that is present in the oil. The peak at 1745 showed the existence of the ester carbonyl functional group of the triglycerides $(C=O)$, and 1235 showed the $\mathrm{C}-\mathrm{O}$ stretch. Aliphatic groups were observed in many compounds that the infrared spectroscopies are likely to encounter. The most important vibrational modes are the $\mathrm{C}-\mathrm{H}$ stretching around $3000 \mathrm{~cm}^{-1}$ and the $-\mathrm{CH}$ deformation modes around $1460 \mathrm{~cm}^{-1}$ and $1380 \mathrm{~cm}^{-1}$. The $\mathrm{CH} 3$ asymmetric stretching vibration occurred at $2975-2950 \mathrm{~cm}^{-1}$ while the $\mathrm{CH} 2 \mathrm{ab}-$ sorption occurred at about $2930 \mathrm{~cm}^{-1}$. The symmetric $\mathrm{CH} 3$ vibration was observed at $2885-2865 \mathrm{~cm}^{-1}$ while the $\mathrm{CH} 2$ absorption ensued at about $2870-2840 \mathrm{~cm}^{-1}$. The $\mathrm{CH} 3$ asymmetric deformation vibration was seen at $1470-1440 \mathrm{~cm}^{-1}$. Further, this band is overlapped with the $\mathrm{CH} 2$ scissor vibration which is found at $1490-1440 \mathrm{~cm}^{-1}$. The symmetric $\mathrm{CH} 3$ vibration was observed at $1390-1370 \mathrm{~cm}^{-1}$; also, the comparative intensities of the asymmetric $\mathrm{CH} 3$ and the $\mathrm{CH} 2$ bands can be analyzed as an indicator of their proportions present in the molecule. The peak spectra 1152 showed alcohols compounds that contain the hydroxyl $(-\mathrm{OH})$ group. The peak spectra at $3244 \mathrm{~cm}^{-1}$ showed $\mathrm{N}-\mathrm{H}$. 


\section{Conclusion}

The oil extracted using a solvent extraction technique from Moringa stenopetala seed was attempted. The oil extraction process was modeled using RSM. The extraction process parameters, temperature, time, and particle size were optimized for maximizing the oil yield. According to RSM analysis, the optimum process condition to extract the highest oil yield was found to be the combination of the following key parameters. Particle size: $0.83 \mathrm{~mm}$, temperature: $78.82^{\circ} \mathrm{C}$, and extraction time: $5.13 \mathrm{~h}$. Under this condition, the model predicted the oil yield was to be $39.7 \pm 0.32 \%$. The oil extracted from Moringa stenopetala seed showed desirable properties for culinary purposes. The physicochemical properties of the extracted Moringa stenopetala seed oil under the optimized condition were investigated and characterized to be a successful source of edible oil for human consumption.

\section{Data Availability}

Data are included in the article/supplementary material/ references in the article.

\section{Conflicts of Interest}

The authors have no conflicts of interest regarding the publication of this paper.

\section{Authors' Contributions}

The authors performed all the experiments and wrote this paper and also participated in experiment design and laboratory work.

\section{References}

[1] M. A. Aboki, M. Mohammed, S. Musa, and B. S. Zuru, "Physicochemical and anti-microbial properties of sunflower (helianthus annus 1.) seed oil," International Journal of Science and Technology, vol. 2, no. 4, pp. 151-194, 2012.

[2] E. Seifu, "Actual and potential applications of moringa stenopetala, underutilized indigenous vegetable of southern Ethiopia: a review," International Journal of Agricultural and Food Research, vol. 3, no. 4, pp. 8-19, 2014.

[3] D. Mikore and E. Mulugeta, "Determination of proximate and mineral compositions of Moringa oleifera and Moringa stenopetala leaves cultivated in Arbaminch Zuria and Konso, Ethiopia," African Journal of Biotechnology, vol. 16, no. 15, pp. 808-818, 2017.

[4] S. Habtemariam, "The chemistry of moringa stenopetala seed oils," The African and Arabian Moringa Species, pp. 33-48, 2017.

[5] AOAC, Official Methods of Analysis of AOAC, pp. 141-144, USA Assoc. Anal. Communities, Gaithersburg, MD, USA, 2000.

[6] K. Leivisk, "Introduction to experiment design kauko leiviskä university of oulu control engineering laboratory table of contents," 2013.

[7] N. S. Ram Talib, M. I. E. Halmi, S. S. Abd Ghani, U. H. Zaidan, and M. Y. A. Shukor, "Artificial neural networks (ANNS) and response surface methodology (RSM) approach for modelling the optimization of chromium (VI) reduction by newly isolated acinetobacter radioresistens strain ns-mie from agricultural soil," BioMed Research International, vol. 2019, Article ID 5785387, 2019.

[8] S. Abdulmumin, I. I. Izom, A. Mamuda, A. Muhammad, and A. M. Abbas, "Determination of physicochemical properties of electric transformer oil extracted from selected plant seeds in Nigeria," Int. Res. J. Eng. Technol, vol. 4, no. 9, pp. 760-767, 2017.

[9] F. Anwar and U. Rashid, "Physico-chemical characteristics of Moringa oleifera seeds and seed oil from a wild provenance of Pakistan," Pakistan Journal of Botany, vol. 39, no. 5, pp. 1443-1453, 2007.

[10] A. S. Erol, M. M. Özcan, and F. Er, "Composition and characteristics of some seed oils," Asian Journal of Chemistry, vol. 23, no. 4, pp. 1851-1853, 2011.

[11] D. Z. Hsu, P. Y. Chu, and M. Y. Liu, "Extracts of sesame (Sesamum indicum L.) seeds and gastric mucosal cytoprotection," Nuts and Seeds in Health and Disease Prevention, pp. 1019-1027, 2011.

[12] M. Chukwu, C. S. Nwakodo, and M. O. Iwuagwu, "Some physical properties of groundnut (Arachis hypogaea linn) seeds: a review," SSRN Electron. J.vol. 6, pp. 59-66, 2020.

[13] L. L. Dean and T. H. Sanders, "Refractive index and density measurements of peanut oil for determining oleic and linoleic acid contents," Journal of the American Oil Chemists' Society no. February, vol. 90, 2012.

[14] M. K. S. El-kheir, A. A. Alamin, H. N. Sulafa, and A. K. S. Ali, "Composition and quality of six refined edible oils in khartoum state, Sudan," ARPN Journal of Science and Technology, vol. 2, no. 3, pp. 177-181, 2012.

[15] M. Popa, I. Glevitzky, G.-A. Dumitrel, M. Glevitzky, and D. Popa, "Study on peroxide values for different oils and factors affecting the quality of sunflower oil," Sci. Pap. Ser. E. L . Reclam. Earth Obs. Surv. Environ. Eng.vol. 6, pp. 137-140, 2017.

[16] A.-A. Neagu, I. Niţa, E. Botez, and S. Geaca, "A physicochemical study for some edible oils properties," Analele Univ. "Ovidius" Constanta - Ser. Chim, vol. 24, no. 2, pp. 121-126, 2014.

[17] R. M. S. Eldeen and H. Ali, "Physicochemical properties of oil extracted from moringa (moringa oleifera) seeds," Universo, pp. 1-65, 2001.

[18] M. D. Saeed and S. E. Adeniji, "Extraction and physico chemical properties of some edible seed oils sampled in kano metropolis kano state," Bayero Journal of Pure and Applied Sciences, vol. 8, no. 2, pp. 239-244, 2015.

[19] E. G. Hammond, L. A. Johnson, C. Su, T. Wang, and P. J. White, "soybean oil," Edible Oil and Fat Products: Edible Oils, no. 1, , 2003.

[20] S. Dermiş, S. Can, and B. Doru, "Determination of peroxide values of some fixed oils by using the mFOX method," Spectroscopy Letters, vol. 45, no. 5, pp. 359-363, 2012.

[21] C. U. Igwe, V. A. Onwuliri, M. D. Golu's, and N. N. Agha, "Assessment of the quality of some edible vegetable oils consumed in northern," Australian Journal of Basic and Applied Sciences, vol. 5, no. 7, pp. 897-905, 2011.

[22] M. M. Gore, "Extraction and physicochemical characterization of oil from maringa stenopetala seeds," Meta Memo Gore, vol. 11, no. 6, pp. 1-7, 2018. 